\title{
Unresectable Liposarcoma
}

National Cancer Institute

\section{Source}

National Cancer Institute. Unresectable Liposarcoma. NCI Thesaurus. Code C132148.

A liposarcoma which is not amenable to surgical resection. 